\title{
A Review of Virtual Reality-Based Language Learning Apps
}

\section{(Una revisión de apps de realidad virtual para el aprendizaje de idiomas)}

\author{
Anke Berns \\ Salvador Reyes-Sánchez \\ Universidad de Cádiz, UCA (España)
}

DOI: http://dx.doi.org/10.5944/ried.24.1.27486

\begin{abstract}
How to reference this article:
Berns, A., \& Reyes-Sánchez, S. (2021). A Review of Virtual Reality-Based Language Learning Apps. RIED. Revista Iberoamericana de Educación a Distancia, 24(1), pp. 159-177. doi: http://dx.doi.org/10.5944/ried.24.1.27486
\end{abstract}

\begin{abstract}
Research in the area of mobile-assisted language learning (MALL) has shown that the use of mobile devices such as smartphones may offer multiple opportunities for supporting foreign language learning. In addition, the development and increasing accessibility of emerging technologies such as virtual reality (VR) has opened new perspectives in the area of MALL, paving the way for a new research field called virtual reality assisted language learning (VRALL). In this context, the present study aims to identify the trends as well as challenges of VRALL by analysing the most popular of the currently available VR apps that can be downloaded from commercial platforms such as Google Play Store and App Store. However, results suggest that most of the retrieved apps are not specifically designed for foreign language learning, although they can be used for such a purpose. Furthermore, very few of the apps explore the real potential of VR, either providing novel teaching and learning approaches and new types of interaction, or offering novel learning scenarios that could allow the learner to experience a greater sense of immersion and thus facilitate the process of language immersion and language acquisition.
\end{abstract}

Keywords: educational software; language teaching; telecommunications; multimedia system.

\section{Resumen}

La investigación en el área del aprendizaje de lenguas asistido por dispositivos móviles (MALL) muestra que el uso de dispositivos móviles como los smartphones ofrecen una gran 
variedad de posibilidades para facilitar el aprendizaje de lenguas extranjeras. Además, el desarrollo y fácil acceso a las tecnologías emergentes como la realidad virtual (RV) han abierto nuevas posibilidades en el área de MALL, preparando el terreno para un nuevo campo de investigación llamado aprendizaje de lenguas asistido por realidad virtual (VRALL). En este sentido, el presente estudio intenta identificar tanto las tendencias como los retos de VRALL mediante el análisis de las apps de RV más populares que pueden descargarse actualmente de plataformas comerciales como Google Play Store y App Store. Sin embargo, los resultados indican que la mayoría de las apps encontradas no están diseñadas específicamente para el aprendizaje de lenguas extranjeras, aunque pueden usarse con este fin. Además, muy pocas apps exploran el verdadero potencial de la RV, ya sea proporcionando nuevos enfoques de enseñanza-aprendizaje, nuevos tipos de interacción $\mathrm{u}$ ofreciendo nuevos escenarios de aprendizaje que permitan al aprendiente experimentar una mayor sensación de inmersión, y, por tanto, faciliten el proceso de inmersión lingüística y adquisición de la lengua.

Palabras clave: software educativo; enseñanza de lenguas; telecomunicación; sistema multimedia.

The increasing advancements of mobile technologies and the accessibility of new and more sophisticated technologies such as virtual reality (VR), headsets, glasses, gloves and handsets, have created new opportunities for supporting teaching and learning processes across all areas of education, including foreign language learning (Andujar \& Buchner, 2019; Dobrova et al., 2017; Frazier et al., 2018; Freina \& Ott, 2015; Radianti et al, 2020). In fact, VR has been described by Rogers (2019) as the learning aid of the $21^{\text {st }}$ century. In this sense, Jensen and Konradsen (2018) have pointed out the enormous potential of VR technologies to foster the acquisition of cognitive skills, psychomotor skills as well as affective skills. These observations are also in line with those made by other researchers (Chavez \& Bayona, 2018; Krokos et al., 2019; Radianti et al, 2020), who have seen the potential of VR, especially, in facilitating students to better retain information and knowledge and to apply these to real world situations. In this context, one of the main affordances of VR technology is that novel learning scenarios could be developed offering students highly immersive and interactive "real-world" environments (Lee \& Wong, 2008; Merchant et al., 2014; Ryan, 2015; Walsh \& Pawlowski, 2002). Such environments could allow students to move in and directly interact with the environment itself, rather than interacting by means of avatars, which until today has been the norm when learning through virtual environments such as Second Life or multiplayer online games (Berns et al., 2013; Christoforou et al., 2019; Lin \& Lan, 2015). By using technologies such as VR-headsets (e.g., Google Cardboard or Samsung Gear VR) in combination with mobile devices such as smartphones, learning processes, in general, and foreign language learning, in particular, could be enriched, providing learners with novel opportunities to experience and practice learning contents in environments that are 
usually difficult to implement in conventional learning environments (Freina \& Ott, 2015).

In this context, the purpose of the current study is to explore the use of the most recent VR technologies in a very specific area of education, which is foreign language learning and to provide language teachers and researchers with an overview of the currently available and accessible VR-based language learning apps by identifying both current trends in the area of VRALL as well as future challenges. With this purpose in mind, the present study analyses 17 of the most downloaded and popular VR-based apps from commercial platforms such as Google Play Store and App Store. Throughout the analysis, the authors intend to give answers to the following research questions (RQ):

RQ1: What kinds of teaching/learning approaches do commercial VR-based apps provide?

RQ2: Do the apps provide novel opportunities for language immersion?

RQ3: What kinds of interaction modes do the apps provide?

RQ4: What kinds of learning scenarios do the apps provide?

RQ5: What kinds of learning content and language competencies do the apps focus on?

RQ6: What kinds of feedback do the apps provide to guide learners through their learning process?

\section{LITERATURE REVIEW}

A review of the literature shows that although VR is not a new concept and appeared a long time ago (Freina \& Ott, 2015) and in many different forms (Berns et al., 2013; De Freitas, 2006; Garrido-Iñigo \& Rodríguez-Moreno, 2015; Jauregi et al., 2011; Lin \& Lan, 2015), the understanding of VR and its characteristics have changed throughout time due to the rise of new and more sophisticated technologies (Andujar \& Buchner, 2019). Currently, VR is understood as “(...) replacing one's surroundings with new digitally created environments through the use of a head mounted display (...)", providing “(...) new ways (...) to immerse users in wholly novel situations and environments" (Lege \& Bonner, 2017, p. 149). While VR originally gained popularity in the sector of entertainment and especially video gaming, it soon started attracting the interest of a wide range of disciplines and fields from medicine and science to education and, more specifically, foreign language learning (Freina \& Ott, 2015; Lege \& Bonner, 2017; Radianti et al, 2020). With regard to foreign language learning, the use of VR technology could allow learners -especially those with few or no possibilities to travel abroad and hence to acquire the target language through authentic and immersive environments- to have opportunities to experience language and cultural immersion through "real-world" environments (Christoforou et al., 2019; Chung, 2012; Dede, 2009). Some interesting attempts in this direction have been made by studies such as the one carried out by researchers from the Kanda 
University of International Studies (Japan) who employed VR 360 videos to place their English-language learners in the middle of "real world" situations (Frazier \& Roloff-Rothman, 2019). The purpose of the study was fostering students' language skills while raising awareness of global issues such as world religions, environmental issues or the global increase in nationalism or populism. Regarding the added value of using VR 360 videos versus conventional videos, the authors underline especially the fact that students not only felt they were immersed in the world projected but could also take their time exploring the details of the different environments. In addition, the stories told by the people they encountered became more tangible, which allowed greater emotional connections with the videos' subjects as well as a deeper sense of understanding (Frazier \& Roloff-Rothman, 2019).

Another interesting attempt to explore the possibilities of VR 360 videos to strengthen foreign language learning was undertaken by researchers from the University of Cádiz (Spain) who developed a VR German-language app called Let's date! This app aims at fostering students' listening and speaking skills (Berns et al., 2018). By means of VR 360 videos, the app permits learners to immerse themselves in a "real world" scenario (in this case a "dating agency") and to interact with "real people" (in this case with one of the employees of the dating agency). To this end, the app implements a chatbot, that is, a software program able to simulate human conversations with the users by employing natural language (Berns et al., 2018). Interaction takes place by means of voice commands that must be sent by the learner in response to the questions posed by the chatbot. By gathering and storing the answers given by each user of the app, the system is able to constantly enrich the corpus of possible answers, taking into account possible differences amongst users, both in terms of content as well as linguistic forms, and thus creating an environment similar to "real world" interaction (Berns et al., 2018). What distinguishes the app from other VR apps that can be found in the literature (Christoforou et al., 2019; Legault et al., 2019) is, amongst others, its adaptive and constructivist learning approach that permits learners to actively participate in the construction of their own knowledge (Berns et al., 2019).

Another interesting app to promote foreign language learning through interactive VR 360 videos and VR headsets has recently been developed by researchers from the University of Tampere (Finland). The app, called CityCompass VR, has been developed for English, German and Finnish (but is easily scalable for other languages) and aims at promoting situational and collaborative conversational language learning by means of way-finding tasks situated in panoramic views of a city (Kallioniemi et al., 2016; Kallioniemi et al., 2019). To this end, two remotely located students (each one taking a different role) must work collaboratively by navigating panoramic views of a given city (e.g., Berlin, Tampere or New Delhi) and exchange relevant information to reach a preassigned destination. Communication as well as interaction amongst players takes place via head-mounted devices (HMD). 
Another study that explores the potential of VR to promote foreign-language learning not only through the use of VR 360 videos and VR headsets but also through the use of VR handsets is the one carried out by researchers from the Pennsylvania State University (USA) (Legault et al., 2019). The study was undertaken with native English undergraduate students and aimed at measuring the impact of immersive VR applications on students' vocabulary learning versus conventional methods such as word-word paired association (WWA) through paper-based learning materials. To this end, the authors tested the learning impact of two different VR apps: one situated in a VR zoo and another one situated in a VR kitchen. Both focused on the teaching of vocabulary items in Mandarin Chinese. The results obtained from the study highlight not only significant differences in terms of students' learning outcomes when using VR apps compared to when they use conventional learning materials such as WWA, but also differences depending on the app learners had used (VR zoo or VR kitchen). Interestingly, those students who used the VR kitchen app obtained better learning results than those who used the $V R$ zoo app. Such differences are seen as consequences of the different interaction modes each app provides. Whilst the $V R$ kitchen app provides learners with more opportunities to interact with the virtual environment and its objects, the $V R$ zoo offers a greater degree of spatial navigation. Nonetheless, the results from the study seem to indicate that a greater degree of interaction is more beneficial for learning than, for instance, a greater degree of spatial navigation (Legault et al., 2019).

A review of the literature regarding the use and developments of VR apps to enhance foreign-language learning reveals that while there has been a growing trend toward exploring the potential of VR technologies to promote new ways of learning (e.g., situation-based learning, experiential and explorative learning, amongst others) and interaction, most of the apps are not available. This means that language teachers and learners currently rely on commercial apps, many of which are available for free on platforms such as Google Play Store or App Store.

\section{METHODOLOGY}

\section{Research design}

For the current study, 17 of the most downloaded and popular apps for Apple iOS and Google Android mobile phones were analysed (Table 1). The study that has been carried out is a qualitative one, based on an explorative-descriptive approach that intends to analyse the presence or lack of a number of different methodological aspects and learning contents related to foreign language learning and the use of VR (i.e., types of immersion and interaction, types of language instruction and feedback provided, kinds of learning scenarios and learning/teaching approaches used, etc.) For the analysis the authors have used a previously established set of criteria (https://figshare.com/articles/VR apps analysed/12280544) that allowed them 
not only to identify the main characteristics of the currently available commercial VR-based language apps, but also possible future challenges.

\section{Selection of apps}

The list of the selected apps for the analysis was obtained from a search carried out on two of the most popular commercial platforms: Google Play Store (for Google Android) and App Store (for Apple iOS). The search was done on 24 December 2019, and the key terms that were used to identify the apps were "VR and Language Learning" and "VR and Foreign Language Learning. The search on both platforms resulted in a total of 50 apps (i.e., 44 apps from Google Play Store and 6 from App Store), from which, however, 33 had to be excluded since they were related only to language learning but not to VR technology. Regarding the apps excluded, 31 were from Google Play Store and 2 from App Store.

In both cases, the exclusion criteria were based either on the fact that an app was not related to VR technology or that the platform did not provide any access to the respective app. Finally, 17 apps out of the total number of apps retrieved were selected for the current analysis. Nonetheless, it is worth mentioning that although all of them belong to the category of education, not all of them focus on language learning or are specifically designed for foreign language learning. The remaining apps were organized in a dataset and filtered out based on the number of downloads registered by each platform (Table 1 ).

Table 1. Selection of 17 VR-based language learning apps

\begin{tabular}{|l|c|c|c|c|}
\hline \multicolumn{1}{|c|}{ App name } & $\begin{array}{c}\text { Year of } \\
\text { publication }\end{array}$ & Price & $\begin{array}{c}\text { No of } \\
\text { downloads }\end{array}$ & $\begin{array}{c}\text { Last } \\
\text { revision }\end{array}$ \\
\hline Fulldive VR & 2015 & Free + In-App & $5000000+$ & Feb. 2019 \\
\hline Sites in VR & 2013 & Free & $100000+$ & Jan. 2019 \\
\hline Within & 2016 & Free & $100000+$ & Dec. 2019 \\
\hline $\begin{array}{l}\text { Acropolis Interactive } \\
\text { educational 3D }\end{array}$ & 2015 & Free & $10000+$ & May 2019 \\
\hline $\begin{array}{l}\text { VirtualSpeech - VR } \\
\text { Courses }\end{array}$ & 2016 & Free & $50000+$ & Nov. 2019 \\
\hline $\begin{array}{l}\text { VR Education \& learning } \\
\text { 36o }\end{array}$ & 2016 & Free & $1000+$ & Dec. 2016 \\
\hline $\begin{array}{l}\text { Beyond VR } \\
\text { Tower of London } \\
\text { interactive educational } \\
\text { VR 3D }\end{array}$ & 2018 & Free & $10000+$ & Aug. 2018 \\
\hline Learn English VR-House & 2018 & Free & $1000+$ & Feb. 2019 \\
\hline
\end{tabular}




\begin{tabular}{|l|c|c|c|c|}
\hline \multicolumn{1}{|c|}{ App name } & $\begin{array}{c}\text { Year of } \\
\text { publication }\end{array}$ & Price & $\begin{array}{c}\text { No of } \\
\text { downloads }\end{array}$ & $\begin{array}{c}\text { Last } \\
\text { revision }\end{array}$ \\
\hline Mondly VR & 2017 & $€_{3.89}$ & $1000+$ & Mar. 2019 \\
\hline VR Learn English in $3 D$ & 2016 & Free & $1000+$ & Oct. 2016 \\
\hline VR Speech & 2019 & Free + In-App & $500+$ & Nov. 2019 \\
\hline ELC VR Job Interviews & 2019 & Free & $50+$ & Jul. 2019 \\
\hline VR Word Chase & 2016 & $\begin{array}{c}\text { Free (App Store); } \\
\text { Co.99 (Google Play) }\end{array}$ & $50+$ & Dec. 2016 \\
\hline Virtual MISLS & 2019 & Free & $10+$ & Jun. 2019 \\
\hline $\begin{array}{l}\text { ESSA-VR/AR-Language } \\
\text { Learning }\end{array}$ & 2018 & Free & n/a & n/a \\
\hline $\begin{array}{l}\text { Flashcard VR for Google } \\
\text { Cardboard }\end{array}$ & 2016 & Free + In-App & n/a & Dec. 2016 \\
\hline
\end{tabular}

\section{Survey instrument and analysis of the apps}

In order to answer the different RQs posed at the beginning of our research and to identify current trends as well as future challenges regarding the development of VR-based apps, we designed a survey instrument based on the model proposed by (Heil et al., 2016) and adapted by us to the research topic and questions addressed. In line with the questions, the following aspects were addressed: languages and operating system supported, monetization, target students, levels, language content and language competencies, topics and learning scenarios, visual input and types of immersion, teaching/learning approaches provided, types of interaction and feedback provided (Table 2).

Table 2. Overview of the topics and aspects analysed

\begin{tabular}{|l|l|}
\multicolumn{1}{|c|}{$\begin{array}{c}\text { Topics } \\
\text { addressed }\end{array}$} & \multicolumn{1}{c|}{ Aspects analysed } \\
\hline $\begin{array}{l}\text { Languages } \\
\text { Supported }\end{array}$ & Languages that are addressed by the apps \\
\hline $\begin{array}{l}\text { Operating } \\
\text { Systems } \\
\text { supported }\end{array}$ & Apple iOS; Google Android \\
\hline Monetization & $\begin{array}{l}\text { None: freely accessible } \\
\text { Pay to unlock: flat fee to access languages and/or levels } \\
\text { Subscription: user must pay a recurring fee to access the app } \\
\text { In app-ads: advertisement is delivered }\end{array}$ \\
\hline
\end{tabular}




\begin{tabular}{|c|c|}
\hline $\begin{array}{c}\text { Topics } \\
\text { addressed }\end{array}$ & Aspects analysed \\
\hline $\begin{array}{l}\text { Target students } \\
\text { \& levels }\end{array}$ & $\begin{array}{l}\text { Preliminary testing: users are asked to test their language level by } \\
\text { filling in a given language test. } \\
\text { Option to test out activities/levels: users can test out activities/ } \\
\text { levels they want to work on before selecting a specific category. } \\
\text { Manual level selection: users can freely choose the level at which } \\
\text { they want to train. }\end{array}$ \\
\hline $\begin{array}{l}\text { Language } \\
\text { Contents/ Modes } \\
\text { of instruction } \\
\text { (vocabulary, } \\
\text { grammar, } \\
\text { pronunciation) }\end{array}$ & $\begin{array}{l}\text { Vocabulary-isolated units: vocabulary is presented out-of-context } \\
\text { and not related to the virtual environment. } \\
\text { Vocabulary in-context: vocabulary is presented in-context and } \\
\text { related to the virtual environment. } \\
\text { Implicit grammar instruction: users must deduce grammar rules } \\
\text { through context. } \\
\text { Explicit grammar instruction: rules are explained prior to the } \\
\text { activity or when users make a mistake. } \\
\text { No grammar instruction: grammar is neither explicitly nor } \\
\text { implicitly addressed. } \\
\text { Pronunciation: users are asked to pronounce words or sentences } \\
\text { from a given audiofile. }\end{array}$ \\
\hline $\begin{array}{l}\text { Language } \\
\text { Competences } \\
\text { (listening, reading, } \\
\text { speaking) }\end{array}$ & $\begin{array}{l}\text { Listening: users must focus on different words, sentences, } \\
\text { conversations or speeches/passages by listening to an audiofile. } \\
\text { Reading: users must focus on different words, sentences, } \\
\text { conversations or speeches/passages by reading them. } \\
\text { Speaking: users practice speaking by reading out loud words/ } \\
\text { sentences, by interacting with a chatbot or giving a speech in front of } \\
\text { a virtual audience. }\end{array}$ \\
\hline $\begin{array}{l}\text { Topics/Learning } \\
\text { Scenarios }\end{array}$ & $\begin{array}{l}\text { Everyday scenarios: language learning takes place through "real- } \\
\text { world" scenarios (e.g., a shop, house, restaurants, etc.). } \\
\text { Culture-specific scenarios: language learning takes place through } \\
\text { culture-specific scenarios (e.g., important museums, monuments, } \\
\text { etc.). } \\
\text { Professional/academic scenarios: language learning takes } \\
\text { place through professional/academic scenarios (e.g., meeting rooms, } \\
\text { conference or lecture rooms, etc.). }\end{array}$ \\
\hline $\begin{array}{l}\text { Types of } \\
\text { Immersion }\end{array}$ & $\begin{array}{l}\text { Spherical recordings \& panoramic images: real-world images } \\
\text { and environments are provided through } 360 \text {-degree recordings. } \\
\text { Virtual environment: computer-generated environments are } \\
\text { provided. }\end{array}$ \\
\hline $\begin{array}{l}\text { Teaching/ } \\
\text { Learning } \\
\text { Approaches }\end{array}$ & $\begin{array}{l}\text { Drill-based learning: learning takes place through systematic } \\
\text { repetition of vocabulary and grammar items. } \\
\text { Adaptive learning: customized resources and learning activities } \\
\text { are provided to address the user's learning needs. } \\
\text { Constructive learning: learners construct their own knowledge by } \\
\text { actively participating in their learning process. }\end{array}$ \\
\hline
\end{tabular}




\begin{tabular}{|c|c|}
\hline $\begin{array}{l}\text { Topics } \\
\text { addressed }\end{array}$ & Aspects analysed \\
\hline & $\begin{array}{l}\text { Task-based learning: learners are required to use the target } \\
\text { language to accomplish a real-world activity. } \\
\text { Explorative learning: learning takes place through exploration. } \\
\text { The user acquire knowledge by exploring and discovering different } \\
\text { ways of solving a given task inferring the rules behind it. } \\
\text { Experiential learning: learning is based on observation and } \\
\text { interaction with the environment. } \\
\text { Situated-based learning: learning content is contextualized. }\end{array}$ \\
\hline $\begin{array}{l}\text { Types of } \\
\text { Interaction }\end{array}$ & $\begin{array}{l}\text { Interaction with chatbots: users interact with a chatbot through } \\
\text { guided conversations and by selecting their answers from different } \\
\text { options provided by the app. } \\
\text { Sending voice commands: users must send a voice message to } \\
\text { perform a task, or interact with a chatbot or virtual environment. } \\
\text { Interaction with the virtual environment: users interact with } \\
\text { the virtual environment by means of visual contact, touch gestures or } \\
\text { voice commands. } \\
\text { Visual contact: users focus on virtual objects by moving around the } \\
\text { virtual environment and with the help of a VR headset. } \\
\text { Touch gestures: users interact with the app by means of their } \\
\text { fingers, hands, gloves or handsets. } \\
\text { Selecting the correct answer: users select answers from various } \\
\text { possible answers. }\end{array}$ \\
\hline Feedback & $\begin{array}{l}\text { None: no feedback is provided on the correctness of an answer. } \\
\text { Sound effects: different sounds indicate correctness or } \\
\text { incorrectness of an answer. } \\
\text { Visual feedback: colours or icons indicate correctness or } \\
\text { incorrectness of an answer. } \\
\text { Corrective feedback but no editing of mistake required } \\
\text { by the user: feedback is provided but with no need to correct the } \\
\text { committed mistakes in order to be allowed to perform the next task. } \\
\text { Simple textual feedback: short feedback on incorrect answers is } \\
\text { provided. } \\
\text { Textual explanation: rationale for incorrectness of the answer is } \\
\text { provided. } \\
\text { Corrective feedback with editing of mistake: users receive } \\
\text { feedback on their mistakes and must revise and correct them before } \\
\text { being allowed to perform the next task. } \\
\text { Hint or suggestion: users are provided with a hint or suggestion in } \\
\text { order to revise and correct their mistakes. }\end{array}$ \\
\hline
\end{tabular}




\section{ANALYSIS AND RESULTS}

With a view to addressing the aforementioned goals, we will first describe and then evaluate the findings of our analysis.

\section{Languages supported}

A look at the languages supported by the analysed apps reveals that only 4 out of 17 (23.53\%) apps are multilingual: Acropolis Interactive educational $3 D$ (16 languages), Mondly VR (16 languages), Tower of London interactive educational VR $3 D$ (16 languages) and Flashcard VR for Google Cardboard (3 languages). The rest of the apps focus solely on one language, which is English (13 out of 17, 76.47\%). With regard to the languages that are supported the most, we could identify English as the most popular language (17 out of 17 apps, 100\%), followed by French and Spanish (4 out of 17 apps, 23.53\%) and finally, German, Italian, Japanese, Portuguese, Russian, Turkish, Arabic, Chinese, Polish, Swedish, Korean, Finnish and Greek (3 out of 17 apps, 17.65\%). Other languages that are taught are Thai and Hindi/Urdu (1 out of 17 apps, $5.88 \%$ ).

\section{Operating systems supported}

Most of the analysed apps (10 out of 17, 58.82\%) are available on App Store as well as Google Play Store and are thus supported by two operating systems: Apple iOS and Google Android (Fulldive VR, Sites VR, Acropolis Interactive educational $3 D$, VirtualSpeech-VR Courses, Beyond VR, Virtual MISLS, ELC VR Job Interviews, $V R$ Word Chase, VR Learn English in 3D, Within). Five out of 17 apps (29.41\%) are available only for Google Android (Mondly VR, Tower of London interactive educational VR $3 D$, VR Education \& learning 36o, VR Speech, Learn English $V R$-House), followed by two apps (11.77\%) that are only available for Apple iOS (Flashcard VR for Google Cardboard, ESSA-VR/AR-Language Learning).

\section{Monetization}

12 out of 17 apps (70.59\%) are freely accessible, with no payment required to unlock either levels or languages (Fulldive VR, Sites in VR, Acropolis Interactive educational 3D, Virtual MISLS, ELC VR Job Interviews, VR Word Chase, ESSA$V R / A R$-Language Learning, VR Learn English in $3 D$, Within, Tower of London interactive educational VR $3 D$, VR Education \& learning 36o, Learn English VRHouse). Unlike those, three apps (17.65\%) require users to pay a flat rate to unlock languages and/or levels (Flashcard VR for Google Cardboard, Beyond VR, VR 
Speech) and two apps (11.77\%) need a subscription to access the app (Virtual SpeechVR Courses, Mondly VR).

\section{Target students and levels}

None of the apps analysed specify the app's target students and only 1 out of 17 apps (5.88\%) allows the users to manually select the levels they want to practice (VR Speech), whereas the rest of apps (94.12\%) do not offer any placement test.

\section{Learning content}

Although the analysis has shown that 8 out of 17 apps (47.06\%) focus on vocabulary learning and/or pronunciation (VR Word Chase, Mondly VR, VR Education \& learning 36o, Flashcard VR for Google Cardboard, VR Speech, VR Learn English in 3D, Learn English VR-House, ESSA-VR/AR-Language Learning), some of them (4 out of 8,50\%) also focus on grammar (VR Word Chase, Mondly $V R, V R$ Education \& learning $360, V R$ Speech). At the same time, there are other apps (9 out of 17, 52.94\%) that allow their users to practice aspects such as fluency or communication skills that go even beyond foreign language learning (Fulldive $V R$, Sites in VR, Acropolis Interactive educational $3 D$, VirtualSpeech-VR Courses, Beyond VR, Virtual MISLS, ELC VR Job Interviews, Within, Tower of London interactive educational $V R 3 D$ ).

\section{Language competencies}

The majority of the apps (13 out of 17 apps, $76.47 \%$ ) analysed focus on practicing several competencies at the same time. Those competencies are mainly reading and listening, although 5 out of 13 apps also provide opportunities to practice speaking (VirtualSpeech-VR Courses, Beyond VR, VR Word Chase, Mondly VR, VR Speech). Another 4 out of 17 apps (23.53\%) focus solely on one competence, that is, either speaking (ESSA-VR/AR-Language Learning) or reading (Acropolis Interactive educational $3 D$, Sites in $V R$, Tower of London interactive educational VR $3 D$ ).

\section{Topics and learning scenarios}

With regard to the topics and learning scenarios addressed, 6 out of 17 apps (35.29\%) are based on culture-specific scenarios such as important museums, monuments, etc. (Sites in VR, Acropolis Interactive educational 3D, Virtual MISLS, Flashcard VR for Google Cardboard, ESSA-VR/AR-Language Learning, Tower of London interactive educational $V R 3 D$ ), while five apps (29.41\%) focus on everyday scenarios such as a shop, house or restaurant (VR Word Chase, Mondly VR, VR 
Learn English in 3D, VR Speech, Learn English VR-House). Additionally, there are three apps (17.65\%) which focus on both everyday scenarios as well as culturespecific scenarios (Fulldive VR, Within, VR Education \& learning 360). Finally, there are another three apps (17.65\%) that focus on professional and academic scenarios, providing users with opportunities to practice skills such as giving a speech in public, practicing a job interview, etc. (VirtualSpeech-VR Courses, Beyond VR, ELC VR Job Interviews).

\section{Visual input and types of immersion}

Regarding the types of immersion provided by the apps, most of the apps (12 out of 17, 70.59\%) are built on virtual environments (Acropolis Interactive educational 3D, VirtualSpeech-VR Courses, Beyond VR, Flashcard VR for Google Cardboard, ELC VR Job Interviews, VR Word Chase, ESSA-VR/AR-Language Learning, Mondly VR, VR Learn English in $3 D$, Tower of London interactive educational VR 3D, VR Speech, Learn English VR-House), while only three of the 17 apps (17.65\%) provide spherical recordings or panoramic images by means of VR 360 images and/ or videos (Sites in VR, Virtual MISLS, VR Education \& learning 36o), followed by two apps (11.77\%) that provide spherical recordings and computer-generated environments (Fulldive VR, Within).

\section{Teaching/learning approaches and learning dynamic}

The analysis has shown that there is a clear trend towards situated-based learning, with 9 out of 17 apps (52.94\%) providing such learning (VR Learn English in 3D, Learn English VR-House, Fulldive VR, Sites in VR, Acropolis Interactive educational $3 D$, Virtual MISLS, Within, Tower of London interactive educational VR $3 D$, Mondly VR), followed by 4 out of 17 apps (23.53\%) that promote task-based learning (VirtualSpeech-VR Courses, Beyond VR, ELC VR Job Interviews, VR Speech) and three (17.65\%) drill-based learning (Flashcard VR for Google Cardboard, VR Word Chase, VR Education \& learning 360). Interestingly, only 1 out of 17 apps (5.88\%) explores the potential of VR technology to harness explorative learning (ESSA-VR/ $A R$-Language Learning), while none of the apps explore adaptive, constructive or experiential learning approaches. At the same time, it is notable that all of the 17 apps focus on individual learning and none on collaborative learning.

\section{User interaction and interaction modes}

The most frequently used interaction modes are clearly those based on visual contact (13 out of $17,76.47 \%$ ) and touch gestures (12 out of 17, 70.59\%). Less frequently used interaction modes are voice commands ( 8 out of 17 apps, $47.10 \%$ ) 
and chatbots (5 out of $17,29.41 \%$ ). However, the analysis indicates that the majority of apps (11 out of 17,64.71\%) provide different modes of interaction. There are between two and four modes of interaction (VirtualSpeech-VR Courses, Beyond VR, Mondly VR, VR Speech, ELC VR Job Interviews, ESSA-VR/AR-Language Learning, Fulldive VR, VR Word Chase, Sites in VR, Acropolis Interactive educational $3 D$, Tower of London interactive educational VR $3 D$ ). Only a few apps (6 out of 17) provide solely one mode of interaction (Virtual MISLS, Flashcard VR for Google Cardboard, Within, VR Education \& learning 36o, Learn English VR-House, VR Learn English in 3D); in these apps, users can interact either by means of touch gestures or visual contact.

\section{Feedback}

Concerning the feedback provided by the analysed apps, it is noteworthy that only 3 out of 17 apps (17.65\%) provide their users with corrective feedback, requiring them to revise and correct their mistakes before completing the next task. This corrective feedback is provided by means of sound effects and/or visuals - colours and icons (Mondly VR, VR Speech, VR Word Chase). With regard to the rest of the apps analysed, five apps (29.45\%) offer the users at least non-corrective feedback. The latter is provided either by means of visuals-colours, icons (Beyond VR, ELC VR Job Interviews, ESSA-VR/AR-Language Learning) - and sound effects (Flashcard $V R$ for Google Cardboard) or by means of visuals - colours, icons - and simple textual feedback (VirtualSpeech-VR Courses). However, it is remarkable that the majority of the apps analysed (9 out of 17 apps, 52.94\%) do not provide users with any kind of feedback on their performance (Fulldive VR, Sites in VR, Acropolis Interactive educational $3 D$, Virtual MISL, VR Learn English in $3 D$, Within, Tower of London interactive educational VR $3 D$, VR Education \& learning 36o, Learn English VR-House).

\section{DISCUSSION}

The results of the analysis of 17 VR apps highlight that the currently available apps on commercial platforms (e.g., Google Play Store and App Store) still explore very little of the potential of VR technology. Thus, in terms of teaching and learning approaches (RQ1: What kinds of teaching/learning approaches do commercial VRbased apps provide?), it is noteworthy that although 70.59\% of the apps analysed support learning approaches such as situated-based learning (52.94\%) or task-based learning (17.65\%), which clearly favour language learning, less than $6 \%$ of the apps (e.g., ESSA-VR/AR-Language Learning) explore the opportunities for providing novel learning approaches (e.g., explorative, adaptive, constructive or experiential learning); i.e., learning approaches that are generally difficult to implement in conventional learning settings (i.e., classroom-based learning, MOOCs). 
Nonetheless, it is promising that approaches such as drill-based learning are not prevalent (17.65\%). Equally noteworthy is that none of the apps retrieved provide opportunities for fostering collaborative learning, for instance, oral interaction via voice messages with other learners. Instead, all 17 apps focus on individual learning.

Another trend that could be highlighted is related to the second research question (RQ2: Do the apps provide novel opportunities for language immersion?). With regard to language immersion it is remarkable that less than $20 \%$ of the apps provide truly immersive environments (e.g., Sites in VR, Virtual MISLS, VR Education \& learning 360) that allow for experiencing emotions and feelings similar to those experienced in the real world.

Thus, it is surprising that despite the enormous opportunities that VR technology provide for creating highly immersive and "real world" environments (Berns et al., 2018, 2019; Frazier \& Roloff-Rothman, 2019), only $17.65 \%$ of the apps explore the potential of VR 360 images and/or videos, followed by another $17.65 \%$ that provide computer-generated (and thus semi-immersive) environments with spherical recordings (e.g., Fulldive VR, Within). The rest of apps analysed are based on computer generated virtual environments which create a very low sense of immersion.

When analysing the third research question, which addresses the interaction modes provided (RQ3: What kinds of interaction modes do the apps provide?), it is striking that $64.71 \%$ of the apps offer multiple types of interaction: from interaction based on visual contact and touch gestures (which are amongst the most frequently used) to interaction by means of voice commands and/or chatbots. Only $35.29 \%$ of the apps provide only one type of interaction: either by means of visual contact or touch gestures. However, in the case of all apps analysed, interaction via touch gestures is still very basic in the sense that users are only allowed to select different options from the app's menu by means of a finger click (Figure 1).

Figure 1. Interaction via finger click

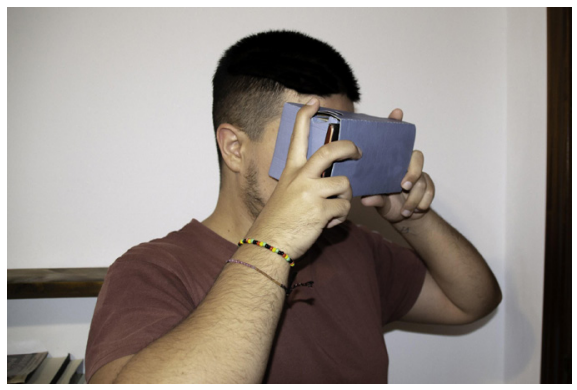

Such options usually refer either to the selection of the level, language and learning topic the user wants to focus on or to the selection of the correct answer. 
Nonetheless, it is significant that none of the apps explore the opportunities VR technology offers for creating interactive environments in which interaction is similar to real-world interaction (Berns et al., 2018; Kallioniemi et al., 2019). This means, that none of the apps analysed permits the user to directly interact with the virtual objects by means of hands, gloves or handsets which could definitely increase the sense of immersion and learning impact, as highlighted by studies such as the one carried out by Legault et al. (2019).

Although the previous data suggest that the majority of commercial apps still face important challenges in terms of exploring novel teaching/learning approaches or developing highly immersive and interactive learning environments, there are nevertheless some promising results regarding the topics and learning scenarios provided. Thus, the analysis of the fourth research question (RQ4: What kinds of learning scenarios do the apps provide?) reveals that $82.35 \%$ of the apps provide culture-specific and/or everyday scenarios, followed by $17.65 \%$ that offer professional and academic training scenarios such as practicing a job interview or giving a speech in public. As a consequence, many of the apps retrieved offer its users those learning scenarios that are often difficult, if not, impossible, to implement in conventional learning settings. Hence, the use of VR technology could provide teachers and students with valuable opportunities to foster certain meaningful topics beyond class.

Equally promising results could be highlighted by the analysis of the fifth research question (RQ5: What kinds of learning content and language competencies do the apps focus on?). A look at the learning content addressed reveals that $52.94 \%$ of the apps focus on the practice of fluency (i.e., confidence, clarity, conciseness, rhythm of speech) and/or communication skills (i.e., verbal communication -listening, speaking; non-verbal communication -eye contact, tone of voice), followed by another 47.06\% that supports vocabulary learning and/or pronunciation. Aspects such as grammar appear to be secondary and are included in only $8.50 \%$ of the analysed apps. With regard to the concrete language competencies addressed, $76.47 \%$ of the apps focus on the practice of several competencies at the same time, with a special focus on reading and listening, followed by speaking. Only a small percentage of apps (23.53\%) focus solely on one competence, which are reading or speaking.

Another aspect that was of interest for our research on VR apps was to what extend the currently available apps help language learners in their learning process by providing, for instance, regular feedback (RQ6: What kinds of feedback do the apps provide to guide learners through their learning process?). Interestingly, only $17.65 \%$ of the apps (Mondly VR, VR Speech, VR Word Chase) provide their users with corrective feedback by means of visuals and/or sound effects, requiring them to revise and correct their mistakes before completing the next task, followed by another 29.45\% (Beyond VR, ELC VR Job Interviews, ESSA-VR/AR-Language Learning, Flashcard VR for Google Cardboard) that provide non-corrective feedback (by means of visuals -colors, icons and simple textual feedback). However, 
it is significant that the majority of apps (52.94\%) do not provide users with any kind of feedback and thus guidance on their performance.

\section{CONCLUSIONS AND FUTURE LINES OF RESEARCH}

The results from our analysis suggest that VRALL, especially with regard to commercial apps, is still on the fringe. In this sense, there are still many challenges that need to be addressed in order to make the most of VR technology for enhancing foreign language learning. Amongst the primary challenges are especially those that involve a major exploration of immersive environments in which learners could experience not solely a greater feeling of immersion, but also a higher degree of "real world" interaction. To this end, learning approaches such as explorative, experiential, constructive and collaborative learning need to be explored much more in future applications. Moreover, the purpose of such approaches must consist of providing learners with more versatile opportunities to interact with the virtual environment in order to foster the acquisition of new knowledge related to the target language and culture, as well as to encourage its application to real-world situations. Other aspects that need to be addressed are those related to the development of more learner-centered applications, which requires an increasing implementation of adaptive learning models based on the use of artificial intelligence as well as the provision of regular feedback on the students' learning process.

\section{ACKNOWLEDGMENTS}

This work was carried out as part of the VISAIGLE project, funded by the Spanish National Research Agency (AEI) with ERDF funds under grant ref. TIN201785797-R.

\section{REFERENCES}

Andujar, A., \& Buchner, J. (2019). The potential of $3 \mathrm{D}$ virtual reality (VR) for language learning: an overview. In I. A. Sanchez, P. Isaias, P. Ravesteijn \& G. Ongena (Eds.), Proceedings of the $15^{\text {th }}$ International Conference Mobile Learning 2019 (pp. 153-156). IADIS. $\quad$ https://doi.org/10.33965/ ml2019 201903Roo2

Berns, A., González-Pardo, A., \& Camacho, D. (2013). Game-like language learning in 3 -D virtual environments. Computers
\& Education, 6o(1), 210-220. https://doi. org/10.1016/j.compedu.2012.07.001

Berns, A., Mota, J. M., Ruiz-Rube, I., \& Dodero, J. M. (2018). Exploring the potential of a $360^{\circ}$ video application for foreign language learning. In $\mathrm{F}$. J. García-Peñalvo (Ed.), TEEM'18. Proceedings of the Sixth International Conference on Technological Ecosystems for Enhancing Multiculturality (pp. 776-780). ACM. https://doi. org/10.1145/3284179.3284309 
Berns, A., Ruiz-Rube, I., Mota, J. M., Dodero, J. M., Castro, E., Ryynanen, O., \& Werner, L. (2019). "Let's date!" A 360-degree video application to support foreign language learning. In F. Meunier, J. Van de Vyver, L. Bradley \& S. Thouësny (Eds.), CALL and complexity - short papers from EUROCALL 2019 (pp. 39-44). Researchpublishing.net. https://doi.org/10.14705/ rpnet.2019.38.983

Chavez, B., \& Bayona S. (2018). Virtual Reality in the Learning Process. In Á Rocha, H. Adeli, L. Reis \& S. Costanzo (Eds.), Trends and Advances in Information Systems and Technologies. WorldCIST'18 2018 (pp. 1345-1356). Springer. https://doi. org/10.1007/978-3-319-77712-2 129

Christoforou, M., Xerou, E., \& PapadimaSophocleous, S. (2019). Integrating a virtual reality application to simulate situated learning experiences in a foreign language course. In F. Meunier, J. Van de Vyver, L. Bradley \& S. Thouësny (Eds.), CALL and complexity - short papers from EUROCALL 2019 (pp. 82-87). Researchpublishing.net. https://doi.org/10.14705/ rpnet.2019.38.990

Chung, L. Y. (2012). Incorporating $3 \mathrm{D}$-virtual reality into language learning. International Journal of Digital Content Technology and its Applications, 6(6), 249-255. https://doi.org/10.4156/jdcta. vol6.issue6.29

Dede, C. (2009). Immersive interfaces for engagement and learning. Science, 323(5910), 66-69. https://doi. org/10.1126/science.1167311

De Freitas, S. (2006). Learning in immersive worlds: a review of gamebased learning. Joint Information Systems Committee. http://www.jisc. ac.uk/media/documents/programmes/ elearninginnovation/gamingr

Dobrova, V., Trubitsin, K., Labzina, P., Ageenko, N., \& Gorbunova, Y. (2017). Virtual Reality in Teaching of Foreign Languages. In E. Malushko, S. Nikolay
\& M. Nikita (Eds.), Proceedings of the $7^{\text {th }}$ International Scientific and Practical Conference "Current issues of linguistics and didactics: The interdisciplinary approach in humanities» (CILDIAH 2017) (pp. 69-74). Atlantis Press. https:// doi.org/10.2991/cildiah-17.2017.12

Frazier, E., \& Roloff-Rothman, J. (2019). Language Learning for Global Citizenship with VR360. Global Issues in Language Education Newsletter, 111, 14-16.

Frazier, E., Bonner, E., \& Lege, R. (2018). A Brief Investigation into the Potential for Virtual Reality: a Tool for $2^{\text {nd }}$ Language Learning Distance Education in Japan. The language and Media Learning Research Center Annual Report, 2, 211216. https://www.kandagaigo.ac.jp/kuis/ cms/wp-content/uploads/2018/04/15-2. pdf

Freina, L., \& Ott, M. (2015). A literature review on immersive virtual reality in education: state of the art and perspectives. In I. Roceanu, F. Moldoveanu, S. Trausan-Matu, D. Barbieru, D. Beliga \& A. Ionita (Eds.), Proceedings of the $11^{\text {th }}$ International Conference eLearning and Software for Education - Rethinking education by leveraging the eLearning pillar of the Digital Agenda for Europe (pp. 133-141). "Carol I" National Defence University.

Garrido-Iñigo, P., \& Rodríguez-Moreno, F. (2015). The reality of virtual worlds: Pros and cons of their application to foreign language teaching. Interactive Learning Environments, 23(4), 453-470. https:// doi.org/10.1080/10494820.2013.788034

Heil, C. R., Wu, J. S., Lee, J. L., \& Schmidt, T. (2016). A Review of Mobile Language Learning Applications: Trends, Challenges, and Opportunities. The Eurocall Review, 24(2), 32-50. https:// doi.org/10.4995/eurocall.2016.6402

Jauregi, K., Canto, S., de Graaff, R., Koenraad, T., \& Moonen, M. (2011). Verbal interaction in Second Life: towards 
a pedagogic framework for task design. Computer Assisted Language Learning, 24(1), 77-101. https://doi.org/10.1080/0 9588221.2010.538699

Jensen, L., \& Konradsen, F. (2018). A review of the use of virtual reality headmounted displays in education and training. Education and Information Technologies, 23(4), 1515-1529. https:// doi.org/10.1007/s10639-017-9676-0

Kallioniemi, P., Sharma, S., Hakulinen, J., \& Turunen, M. (2016). Collaborative Conversational Language Learning with CityCompass. In J. Read \& P. Stenton (Eds.), Proceedings of the The $15^{\text {th }}$ International Conference on Interaction Design and Children (pp. 672-675). ACM. https://doi. org/10.1145/2930674.2938612

Kallioniemi P., Ronkainen K., Karhu J., Sharma S., Hakulinen J., \& Turunen M. (2019) CityCompass VR - A Collaborative Virtual Language Learning Environment. In D. Lamas, F. Loizides, L. Nacke, H. Petrie, M. Winckler \& P. Zaphiris (Eds.), Human-Computer Interaction INTERACT 2019 (pp. 540-543). Springer. https://doi.org/10.1007/978-3-03029390-1 33

Krokos, E., Plaisant, C., \& Varshney, A. (2019). Virtual memory palaces: immersion aids recall. Virtual Reality, 23, 1-15. https://doi.org/10.1007/s10055018-0346-3

Lee, E. A.-L., \& Wong, K. W. (2008). A review of using virtual reality for learning. In Z. Pan, A. D. Cheok, W. Müller \& A. El Rhalibi (Eds.), Transactions on Edutainment I (pp. 231-241). Springer. https://doi.org/10.1007/978-3-54069744-2 18

Legault, J., Zhao, J., Chi, Y., Chen, W., Klippel, A., \& Li, P. (2019). Immersive Virtual Reality as an Effective Tool for Second Language Vocabulary Learning. Languages, 4(1), 1-32. https://doi. org/10.339o/languages4010013
Lege, R., \& Bonner, E. (2017). The state of virtual reality in education. The language and Media Learning Research Center Annual Report, 149-156. http://id.nii. ac.jp/1092/00001460/

Lin, T. J., \& Lan, Y. J. (2015). Language learning in virtual reality environments: Past, present, and future. Journal of Educational Technology \& Society, 18(4), 486-497.

Merchant, Z., Goetz, E. T., Cifuentes, L., Keeny-Kennicutt, W., \& Davis, T. J. (2014). Effectiveness of virtual realitybased instruction on students' learning outcomes in K-12 and higher education: A meta-analysis Computers \& Education, 70, 29-40. https://doi.org/10.1016/j. compedu.2013.07.033

Radianti, J., Majchrzak, T. A., Fromm, J., \& Wohlgenannt, I. (2020). A systematic review of immersive virtual reality applications for higher education: Design elements, lessons learned, and research agenda. Computers \& Education, 147, 1-29. https://doi.org/10.1016/j. compedu.2019.103778

Rogers, S. (2019). Virtual Reality: The learning aid of the $21^{\text {st }}$ century. Forbes. https://www.forbes.com/ sites/solrogers/2019/03/15/virtualreality-the-learning-aid-of-the-21stcentury/\#7b5ad441139b

Ryan, M. L. (2015). Narrative as virtual reality 2: Revisiting immersion and interactivity in literature and electronic media (Vol. 2). Johns Hopkins University Press.

Walsh, K. R., \& Pawlowski, S. D. (2002). Virtual reality: A technology in need of IS research. Communications of the Association for Information Systems, 8(1), 297-313. https://doi. org/10.17705/1CAIS.00820 


\section{ACADEMIC AND PROFESSIONAL PROFILE OF THE AUHORS}

Anke Berns currently holds a position as a senior lecturer in German at the University of Cadiz (Spain). Her research interests focus mainly on the use of emerging technologies and the development of teaching and learning materials for foreign language learning with a special focus on MALL and VRALL. Since 2014 she has been an active member of the SP\&FM research group (University of Cádiz). https://orcid.org/0000-0003-3129-7209

E-mail: anke.berns@uca.es

Salvador Reyes Sánchez is a postgraduate student of English Philology and currently collaborating with the Department of French and English Philology at the University of Cádiz. His research focuses on MALL, the development of teaching and learning materials for foreign language learning with a special focus on the development of language apps. Since 2016 he has been collaborating with the German as a Foreign Language Department participating in the development of different language apps. https://orcid.org/o00o-0003-1281-1815

E-mail: salvador.reyessanchez@alum.uca.es

Address:

Facultad de Filosofía y Letras Universidad de Cádiz (UCA)

Av. Doctor Gómez Ulla, s/n

Cádiz (España)

Date of receipt: $11 / 05 / 2020$

Date of acceptance: $23 / 07 / 2020$

Date of layout: 05/08/2020 